\title{
TÉCNICA IMPRONTAS DE HOJAS. ALGUNAS REFLEXIONES ACERCA DE SU NOVEDOSO REGISTRO EN LA VERTIENTE ORIENTAL DE LA CORDILLERA DE LOS ANDES.
}

\author{
ALBERTO E. PÉREZ* Y VERÓNICA A REYES A."*
}

\begin{abstract}
RESUMEN
Se describen dos conjuntos cerámicos obtenidos de San Martín de los Andes, Provincia de Neuquén, Argentina, que presentan en sus superficies externas evidentes improntas de hojas en negativo. Posteriormente, se comparan ambos conjuntos con algunos contextos chilenos donde el rasgo improntas de hojas en negativo aparece. La presencia de hallazgos similares de este tipo, obtenidos en ambientes lacustres boscosos de ambas vertientes de la cordillera de los Andes, permite discutir la problemática de la territorialidad que pudieron tener a ambos lados de la cordillera, los grupos portadores de una desarrollada tecnología alfarera caracterizada como Complejo Pitrén.
\end{abstract}

PALABRAS CLAVES: Improntas de hojas, vasijas cerámicas, complejo Pitrén, ambientes lacustres boscosos, norpatagonia, Argentina y Chile.

\section{PRINTS OF LEAVES TECNIQUE. SOME THOUGHTS ABOUT THIS NEW RECORD IN THE EASTERN SLOPE OF THE CORDILLERA DE LOS ANDES.}

\section{ABSTRACT}

Two pottery sets from San Martín de los Andes, Neuquén, in Argentina, which show evident prints of leaves in negative on their external surfaces are described in this paper/article. This feature/characteristic mentioned above allows us to analize similar findings obtained from wooded lacustrine environment located on the Western slope of the Cordillera de los Andes. Besides, we may also focus on territorial issues related to groups settled on both slopes of the mountain range who developed a pottery technology described as Pitrén Complex.

KEY WORDS: Prints of leaves, pottery set, Pitrén Complex, wooded lacustrine environment, Nothpatagonian, Argentina and Chile.

\footnotetext{
Becario Doctoral UBA. FHN Félix de Azara, CIEDE y Subsecretaría de Cultura de San Martín de los Andes, Neuquén, República Argentina. Cap. Drury 665 (8370). arqueo.meliquina@gmail.com.

** Licenciada en Arqueología. El Salado 628. La Florida. Santiago. Chile. vreyesalvarez@vtr.net
} 


\section{INTRODUCCIÓN}

A partir de los trabajos de investigación llevados a cabo en forma sistemática en la Localidad Arqueológica Meliquina (en adelante LAM) y los trabajos de rescate efectuados por personal de la Subsecretaria Municipal de Cultura de San Martín de los Andes, se presenta un acotado número de artefactos arqueológicos de características singulares para la región. Se trata de vestigios de alfarería que presentan evidencias macroscópicas del uso de una técnica de cocción singular, la cual se caracteriza por dejar evidentes improntas de hojas en negativo sobre la superficie de la cerámica, como producto presuntamente del material combustible utilizado, o bien, como resultado de una aplicación intencional con fines decorativos. Esto significa que no hay aún un consenso entre los especialistas si se trata de un "estilo decorativo" o el efecto involuntario del proceso de cocción, al menos hasta contar con resultados de estudios experimentales (Castro y Varela 1990). Esta técnica ha sido comúnmente descrita entre los artefactos cerámicos que caracterizan a los conjuntos denominados "Complejo Pitrén" (Menghin 1962) y por lo tanto, su distribución espacial se encuentra tradicionalmente limitada al sector occidental de la Cordillera de los Andes, específicamente al territorio chileno.

Si bien la presencia de cerámica Pitrén en contextos neuquinos no es una novedad, buena parte proviene del estudio de colecciones particulares y museográficas (Schobinger 1958, Hajduk 1978, 1985), mientras que otras de excavaciones en la provincia de Neuquén (Fernández 1988-89; Hajduk 1978, 1986; Silveira 1996; Pérez 2006), aunque existen menciones sobre su presencia en Río Negro (Bellelli 1991) y Chubut (Bellelli et al. 2008). En la mayoría de los casos estos conjuntos han sido interpretados como escasos hallazgos aislados, y su presencia ha sido explicada como el producto de intercambios con poblaciones con territorialidad en el ámbito transcordillerano (Silveira 1987, 1999, 2003), a excepción de algunos conjuntos de Bajo de Añelo y Alumine-Moquehue, donde resaltan el parentesco de estos conjuntos con sitios del occidente cordillerano (Hajduk 1978). A partir de estudios en la localidad arqueológica Meliquina se ha postulado que la presencia de artefactos arqueológicos asociados al Complejo Pitrén, no son escasos ni aislados en la patagonia noroccidental (Pérez 2006). Sin embargo, pensamos que las muestras están sesgadas debido al uso de las variedades "Modelado" y "Pintado" -principalmente pintura resistente- como fósil guía del Complejo Pitrén, variedades que son raras incluso en contextos chilenos, cuyos porcentajes en sitios habitacionales no superan el 3\% (Adán y Alvarado 1999). En esta misma proporción aparece en algunos contextos domésticos del lado oriental de los Andes. La presencia de caracteres similares entre los conjuntos cerámicos utilitarios de ambas vertientes de la cordillera es fundamental entonces, y en este caso puntual, cobra gran importancia la presencia de una de las técnicas de cocción o estilo decorativo más singular y característico de la alfarería temprana del área centro sur de Chile, las improntas de hojas.

\section{PROBLEMA Y OBJETIVOS}

En este trabajo presentaremos y caracterizaremos, a partir de su descripción, dos conjuntos de artefactos cerámicos novedosos recuperados en contextos de San Martín de los Andes, Parque Nacional Lanín, provincia del Neuquén, Republica Argentina. Uno procedente de un acompañamiento funerario ubicado sobre el cordón Chapelco, que fue intervenido no sistemáticamente y el otro proveniente de un sitio habitacional a cielo abierto ubicado en las cercanías del lago Meliquina. En un acápite posterior se comparan brevemente y en forma cualitativa las principales semejanzas observadas entre estos dos conjuntos cerámicos argentinos con las vasijas de contextos chilenos que presentan improntas de hojas en negativo. Si bien, la presencia de cerámica Pitrén en Argentina hasta la fecha ya contaba con antecedentes, su registro ha sido consignado como escaso y producto de intercambio entre sociedades distintas que ocupaban las vertientes opuestas de la cordillera de los Andes, pasando ésta última a ser concebida como una posible limitante natural o cultural. Las alteraciones postdepositacionales y procesos de formación inherentes a estos artefactos son completamente desconocidos regionalmente, por lo que, se propone hacer un primer acercamiento a algunas variables que puedan redundar en aspectos de la visibilidad de estos conjuntos. Además, se describe por primera vez para Argentina la presencia de cerámica con improntas de hojas en su superficie, características del Complejo Pitrén, por lo que se 
amplia la distribución espacial de esta técnica y dado el contexto en que se encuentran estos materiales, se aportan elementos de gran utilidad para contrastar los postulados sobre la existencia de una expresión cordillerana oriental del Complejo Pitrén para momentos tardíos (ver Aldunate 1989), caracterizada por un importante énfasis en la caza y recolección de productos del bosque.

\section{DESCRIPCIÓN DEL ÁREA DE ESTUDIO}

De acuerdo a su ubicación en la Cordillera de los Andes, el relieve del área de estudio se caracteriza por ser típicamente montañoso, con pendientes pronunciadas y alturas promedio de entre 900 y 1900 msnm (Mermoz et al. 1997). En el paisaje predominan las geoformas de origen glaciario, sobre todo las de tipo erosivo, como cuencas lacustres y valles en $\mathrm{U}, \mathrm{y}$ también rastros de acción volcánica (Mermoz et al. 1997). Biogeográficamente, el área de estudio se encuentra enmarcada dentro del Distrito Andino-Patagónico y en la zona andina, donde el clima es mayoritariamente frío y húmedo. La orografía de la región es, en gran medida, responsable de la abundante cantidad de lluvia que reciben las áreas adyacentes a las montañas. Los vientos cargados de humedad que se desplazan de oeste a este son interceptados por las grandes elevaciones de la cordillera de los Andes. El efecto que se produce como resultado es la condensación de la humedad y la consecuente descarga de importantes lluvias a ambos lados de la Cordillera, dominantes del lado chileno de la cordillera (Paruelo et al. 1998). En invierno se registran temperaturas medias de $4^{\circ} \mathrm{c}$, mientras que en verano, llegan a los $20^{\circ}$ c. Las precipitaciones se producen mayormente durante el invierno. Fitogeográficamente, corresponde a la provincia Altoandina (Distrito Austral) y Bosque caducifolio (sector oriental del bosque que responde a condiciones algo más secas) y Valdiviano (una superficie bastante restringida dentro del área, adyacente a la frontera con Chile, donde se registran las condiciones más húmedas, con lluvias que superan los 4.000 $\mathrm{mm}$ anuales). El ambiente de bosque comprende a las provincias fitogeográficas Altoandina -Distrito Austral- y la Subantártica del Bosque Caducifolio y Valdiviano -Distrito del Pehuén-, que se distinguen de acuerdo a las características de las asociaciones vegetales (Cabrera 1971). La fauna autóctona carac- terística del bosque incluye varias especies de aves, mamíferos, reptiles, peces y anfibios (Mermoz et al. 1997). El clima del área es de tipo frío y húmedo, típico de la cordillera Patagónica. Los registros más cercanos procedentes de estaciones privadas en el valle de Meliquina muestran un régimen de precipitaciones elevado, que oscila anualmente entre los 1.500 y $2.000 \mathrm{~mm}$.

\section{ANTECEDENTES}

1a. Acerca de la distribución espacial y temporal de las improntas de hojas en sitios chilenos del complejo pitrén

En la vertiente occidental de los Andes el Complejo Pitrén ha sido definido como la primera ocupación agroalfarera de la Araucanía o región centro sur de Chile y sus manifestaciones se extenderían desde el río Bío-Bío hasta el lago Llanquihue, además del centro y norte de la provincia de Neuquén en Argentina (Aldunate 1989). Siguiendo a Aldunate (1989), este complejo estaría definido básicamente a partir de contextos y vasijas mortuorias. En este sentido, las ocupaciones Pitrén corresponderían básicamente a una serie de cementerios tempranos en general de tamaño pequeño y aislados entre sí, sugiriendo el establecimiento de grupos familiares reducidos, dotados de movilidad estacional, cuyo énfasis económico sería la caza y la recolección. El mismo autor señala una mayor concentración de sitios en los lagos de la zona precordillerana (Aldunate 1989; Adán y Alvarado 1999), y en el valle central en las riberas de ríos y lagos. De acuerdo a la perpetuidad que muestran ciertos elementos cerámicos Pitrén, tanto en tiempos alfareros tardíos como históricos, $e$ inclusive actuales, el autor plantea que Pitrén puede ser considerada como una tradición cerámica (Aldunate 1989).

En términos cronológicos las manifestaciones Pitrén más antiguas se han constatado dentro de los primeros quinientos años de nuestra era ${ }^{1}$, mientras

1 Estas primeras ocupaciones corresponden a los sitios P10-1 de la isla Mocha de la VIII Región de Chile (Sánchez 1997), a los sitios Alero Quino (Quiroz et al. 1997), Huimpil (Gordon 1984), Shell Norte y Campus Andrés Bello (Adán y Mera 1997a; Mera y Adán 1997) del valle central de la IX Región de Chile y al cementerio Los Chilcos de la cordillera lacustre de la XIV Región de Chile (Adán y Reyes 2000). 
que las más tardías se extenderían hasta ca del año 1.000 dC. Cabe destacar sin embargo, que en áreas marginales como p.e sectores insulares (Quiroz y Sánchez 2005) o lacustres cordilleranos (Reyes et al. 2003-2004), es posible encontrar contextos de este complejo con fechas más tardías, cercanas a los años $1.200-1.400 \mathrm{dC}$.

Entre la alfarería que conforma el complejo Pitrén, se encuentran una serie de tipos cerámicos que ya en los años '60 habían sido reconocidos por los pioneros estudios realizados en el área centro sur (Menghin 1962, Berdichewsky y Calvo 1972-1973), y que posteriormente investigadores contemporáneos retoman, sistematizan y refinan para dar origen a nuevas tipologías decorativas y morfológicas (Aldunate 1989; Adán 1997; Adán y Mera 1997a; Adán y Alvarado 1999). Como parte importante de los elementos decorativos que caracterizarían a este complejo o tradición cerámica (Aldunate 1989; Adán y Mera 1997b; Adán et al. 2001) se encuentra la pintura resistente. En términos generales, este tipo de decoración se define por el uso de los colores negro y rojo, disponiéndose casi exclusivamente sobre la categoría morfológica jarro (Adán y Alvarado 1999). En cuanto a los motivos y configuración de los mismos, algunas tipologías decorativas establecidas recientemente han logrado singularizar diversas variedades de diseños, los cuales en todos los casos se componen de elementos geométricos (Adán 1997).

En este último sentido, la presencia de improntas de hojas en negativo, sería la única excepción registrada respecto a la elección del uso de motivos geométricos para modificar la superficie de las vasijas mediante esta técnica. Así, las improntas aparecen tanto en la superficie externa como interna de diversos tipos morfológicos de vasijas, los que si bien en su mayoría corresponden a jarros, incluyen también ollas, botellas, tazas, escudillas y cuencos (Adán y Mera 1997b). De esta manera, la presencia de improntas de hojas es un rasgo ampliamente manifiesto en diversos contextos Pitrén y por lo tanto, podría ser considerado junto a los otros elementos ceramológicos que lo definen, como diagnóstico de este temprano complejo alfarero. Lo anterior sin embargo, no implica que se haya identificado un patrón normado en el tipo y emplazamiento de estas "hojas" en negativo, por lo cual y como fuera señalado en la introducción de este artículo, no existe consenso sobre el carácter intencional de la elección y aplicación de este rasgo. Pese a lo anterior, podemos señalar que lo que sí estaría fuera de discusión, es la amplia dispersión geográfica y temporal que manifiestan las improntas de hojas dentro de las vasijas monocromas de diversos yacimientos Pitrén de la vertiente occidental de la cordillera andina. Pero a pesar de esta significativa presencia, no ha existido una adecuada documentación de este rasgo, obliterando de algún modo su real magnitud.

De esta forma, vemos que en diversas publicaciones de sitios asignados al complejo Pitrén, los cuales en su mayoría son de carácter mortuorio, no se menciona la presencia del rasgo improntas de hojas dentro de las descripciones de las vasijas funerarias. En cuanto a la literatura clásica, es el caso por ejemplo del trabajo ofrecido por Menghin (1962), en el cual si bien se informan acuciosamente los tipos de vasijas descubiertos en el sitio tipo Pitrén, no se hace mención de cántaros que contengan improntas de hojas (Menghin 1962). En esta misma línea, otros importantes ejemplos de esta ausencia lo constituyen la reseña elaborada por Gordon para el sitio Huimpil, del cual además se obtuvo el primer fechado absoluto para Pitrén en el lado chileno (Gordon 1984) y la publicación de Berdichewsky y Clavo (1972-1973) sobre los hallazgos Pitrén del sector lacustre cordillerano de la región del Calafquén.

Respecto a la literatura elaborada a partir de investigaciones recientes sucede algo similar. Es el caso por ejemplo de los reportes de importantes sitios ubicados en el valle central del río Cautín, en las cercanías de la ciudad de Temuco, como son los cementerios Km. 15 Licanco Chico y Km. 20 Lof Mahuida excavados en el contexto de la construcción de un by pass (Ocampo et al. 2001). En estos verdaderos panteones se recuperaron más de 500 piezas asociadas a contextos mortuorios, sin embargo, en la descripción de las mismas no se observa ninguna referencia al rasgo improntas de hojas. Otro ejemplo de estudios contemporáneos lo constituye un artículo sobre el cementerio Los Chilcos de la región del Calafquén (Adán y Reyes 2000). De allí se rescataron 12 vasijas asociadas a fosas funerarias y en su publicación no se reporta la presencia de improntas de hojas (Fig. 1).

Gracias a una base de datos generada a partir de un importante trabajo de clasificación y análisis de 


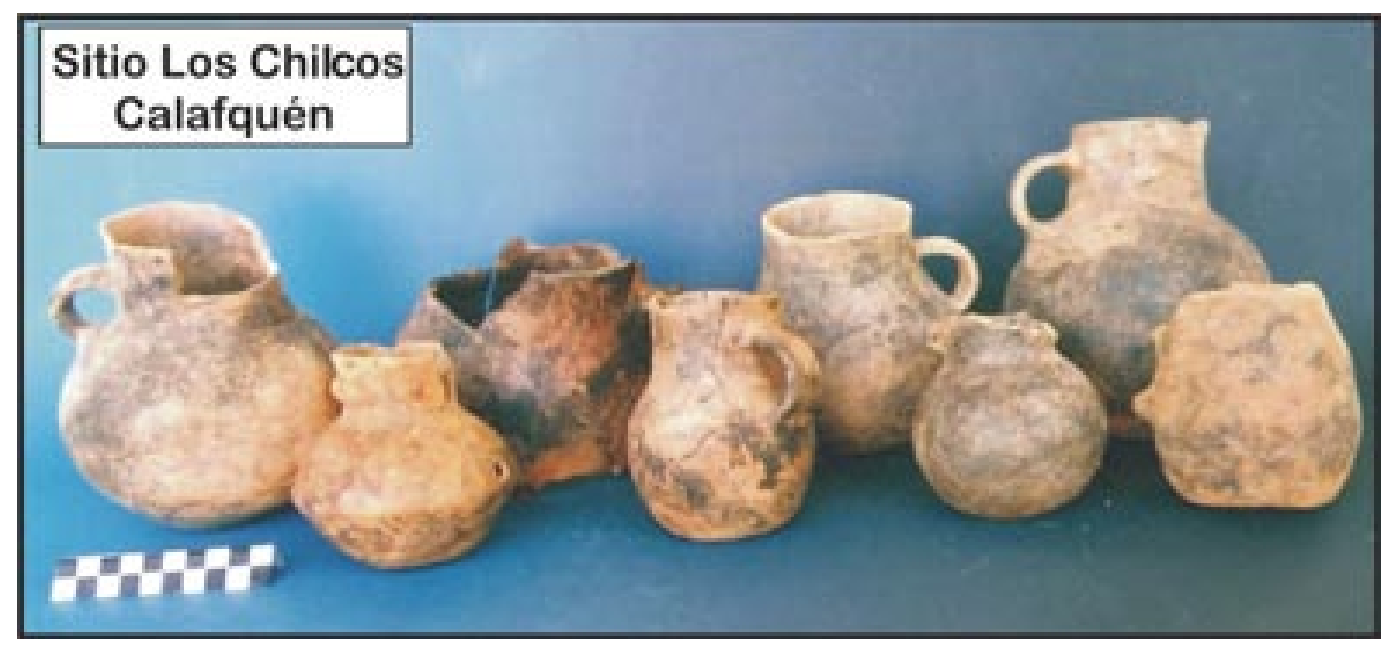

Fig. 1. Conjunto de ceramios con improntas de hojas. Sitio Los Chilcos, Lago Calafquén, Chile.

alrededor de 400 cántaros adscritos al complejo Pitrén, que se encontraban depositados en las colecciones arqueológicas de diversos museos de la Araucanía (Adán y Mera 1997b; Mera y Adán 1997), hoy día sabemos con certeza que sí fueron rescatadas en el lago Calafquén vasijas que manifestaban el rasgo improntas de hojas. Estas provenían de algunos de los cementerios Pitrén excavados por Berdichewsky y Calvo (1972-1973) (Fig. 2), del sitio tipo Pitrén (Menghin 1962) (Fig. 2) y de Los Chilcos (Adán y Reyes 2000) (Fig. 2).

Para el caso del cementerio Huimpil o de aquellos localizados en las cercanías del by pass de Temuco, hasta no realizar una revisión sistemática de las piezas cerámicas obtenidas, quedará la duda sobre la presencia de este rasgo ${ }^{2}$.

Lo mismo sucede con algunas ocupaciones costeras Pitrén de la porción septentrional de la Araucanía chilena. Es el caso de las investigaciones realizadas en la isla Mocha, VIII Región, las cuales si bien, han reportado pintura negativa negro sobre rojo en diversos sitios mixtos habitacionales y de sepultura, como p.e en los sitios P $31-1^{3}, \mathrm{P} 21-1^{4}, \mathrm{P} 22-1^{5}$ y P25-16, a juzgar por las descripciones cerámicas

2 Aunque es muy probable que sus vasijas lo presenten, ya que en diversos sitios Pitrén ubicados en las cercanías de la ciudad de Temuco, cuenca del río Cautín, ha sido registrado (Adán y Mera 1997b).

(Sánchez et al. 1994).

(Quiroz y Sánchez 2005).

(Sánchez 1997).

(Sánchez 1997). ofrecidas, en ellos no habrían vasijas con improntas de hojas (Quiroz y Sánchez 2005; Sánchez et al. 1994, Sánchez 1997).

Pese a lo anterior, queda nuevamente la duda sobre la presencia de vasijas con improntas de hojas en negativo en estos asentamientos costeros septentrionales, ya que en la base de datos del estudio de piezas completas antes señalado hay registro de ellas para esta zona. Estas provendrían de las zonas de Tirúa, Cañete, Angol y alrededores e inclusive desde la misma isla Mocha y corresponderían a los tipos morfológicos ollas, jarros simétricos y asimétricos, botellas, tazas y escudillas (Adán y Mera 1997b) ${ }^{7}$. En estas vasijas se constatan improntas de hojas en sus superficies externas e internas (Adán y Mera 1997b).

Como una importante excepción a esta ausencia de registros dentro de la literatura especializada del rasgo que nos compete, se encuentra el reporte del sitio Escuela Collico ubicado en la localidad de Loncoche, sección media de la cuenca de Valdivia, XIV Región de Chile (Mera y Munita 2006). En él se encuentra las descripción de las vasijas mortuorias rescatadas, en donde se expone la presencia de improntas de hojas en al menos dos cántaros; uno sería un jarro y el otro un jarro sin asas y cuello corto (Adán et al. 2007). Este último es denominado

7 De acuerdo a este estudio de colecciones museológicas de la Araucanía, en general los tipos morfológicos que presentan improntas de hojas en negativo corresponden a estas mismas categorías. Agregándose a ellos la forma cuencos (Adán y Mera 1997b). 


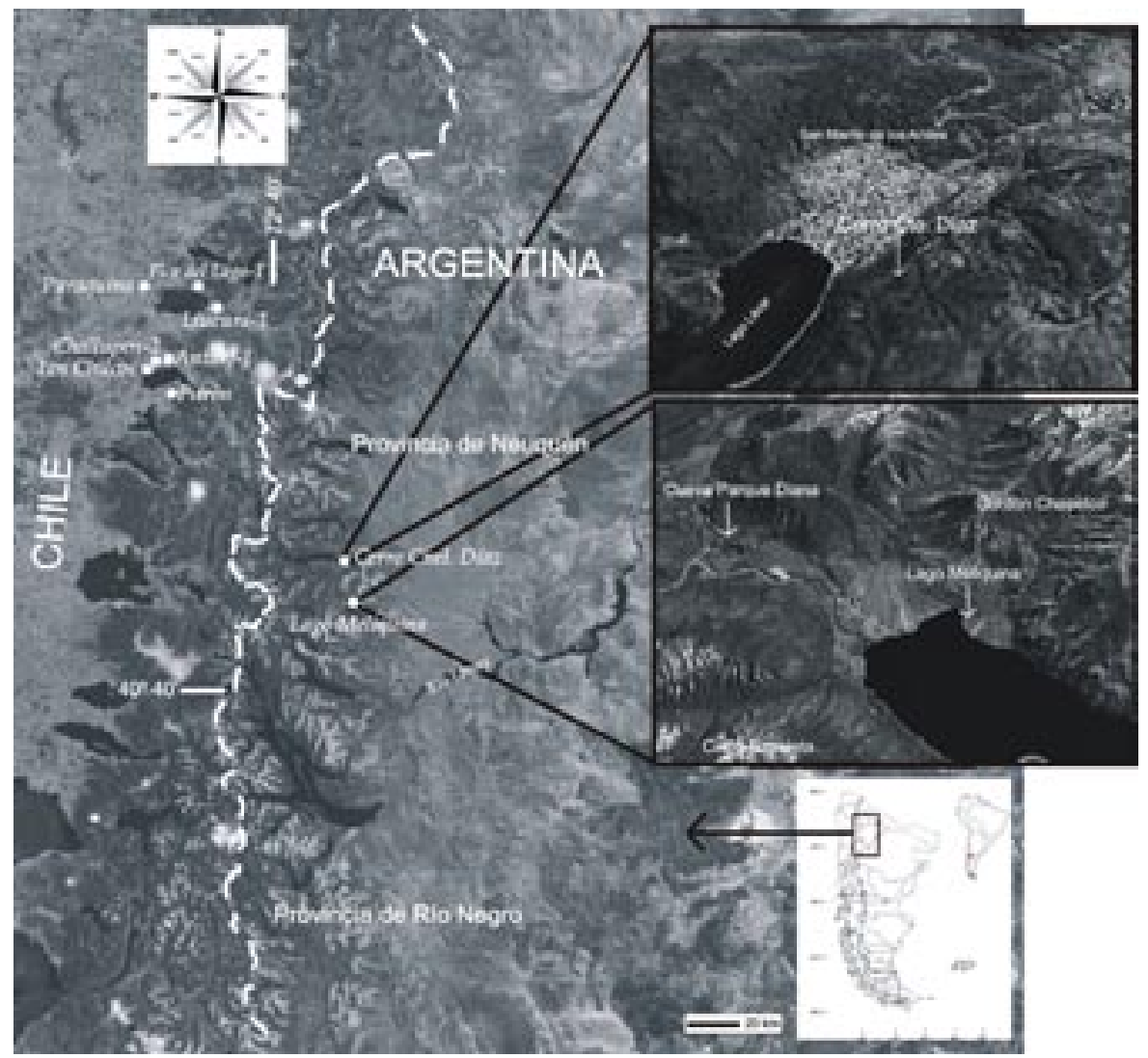

Fig. 2. Ubicación de los conjuntos analizados y ubicación de algunos sitios precordilleranos chilenos con improntas de hojas.

por lo autores como un tipo morfológico nuevo, en consideración a la tipología formal Pitrén que los mismos investigadores habrían creada años antes (Adán 1997; Adán y Mera 1997a; Adán y Mera 1997b; Adán y Alvarado 1999; Mera y Adán 1997). De acuerdo al análisis de las vasijas cerámicas identificadas en este cementerio y en función de las fechas obtenidas, que lo datan en el año 1.045 +/- 100 AP, este asentamiento se adscribiría al complejo Pitrén (Mera y Munita 2006).

Como parte de este grupo de estudios contemporáneos en que se reconoce la presencia del rasgo improntas de hojas, se puede señalar un reciente informe realizado sobre la fragmentería cerámica recuperada del sitio habitacional Licura-1, ubicado en las cercanías del lago Villarrica, IX Región de Chile (Fig. 2). En él se describen dos fragmentos decorados con improntas de hojas por el exterior con técnica negativa; siendo uno de ellos parte de una vasija con asa con protúbero (Donoso y Gallego 2008). Si bien para este asentamiento aún no se cuenta con fechados absolutos, en función de su contexto cerámico ha sido adscrito al complejo Pitrén (Donoso y Gallego 2008). En otro estudio menos reciente, pero también realizado para la región lacustre cordillerana de la XIV Región de Chile, se acusa la presencia de cerámica doméstica Pitrén con improntas de hojas en el asentamiento Antilef-1 del lago Calafquén (Fig. 2), cuya fecha es de 990 dC (Reyes et al. 2003-2004). En esa ocasión las autoras no interpretaron este rasgo como resultado de una acción decorativa intencional, si no que más bien, como producto del proceso de manufactura de la pieza (cocción) (Reyes et al. 2003-2004).

En relación al período alfarero tardío del área centro sur de Chile, siguiendo a Adán y Alvarado (1999) vemos que el tipo de decoración donde priman los diseños geométricos con técnica negativa desaparece, pero siguen registrándose en escasa frecuencia vasijas monocromas con improntas de hojas (Adán y Alvarado 1999). 
Así por ejemplo, los únicos sitios domésticos tardíos que consigan en su reporte este rasgo cerámico son Flor del Lago-1 y Puraquina, ubicados en las cercanías de las costas del lago Villarrica (Fig. 2). Para el caso de Flor del Lago-1, fueron rescatados dos fragmentos decorados con improntas de hojas, uno de los cuales las manifiesta por el exterior e interior y correspondería al cuello de un cántaro. Dentro de este mismo depósito se registró cerámica roja sobre engobe blanco (El Vergel o Valdivia), fragmentos con lentejuelas al pastillaje y otros con acanalados, todos elementos asignados al período alfarero tardío de la zona (Donoso y Gallego 2008). Aunque este sitio aún no tiene fechas, dadas estas características cerámicas, ha sido adscrito al período alfarero tardío del área centro sur (posterior al año 900-1.000 dC). El otro sitio denominado Puraquina, posee una fecha de 515 AP (Mera et. al 2004) y en él fueron registrados una serie de fragmentos monocromos con este rasgo.

Para finalizar, es preciso señalar que para otros sitios alfareros tardíos del área centro sur, tanto de orden funerario como habitacionales, tampoco ha sido informada la presencia de improntas de hojas en negativo dentro de las vasijas. Es posible que al igual que lo sucedido en el caso de los sitios Pitrén arriba reseñados, esta ausencia se deba a un problema de registro y clasificación del material, o bien, para el caso de los asentamientos domésticos al hecho de que la visualización de este rasgo a nivel de fragmentería es muy dificultosa.

1b. Acerca de la distribución espacial y temporal de las improntas de hojas en sitios argentinos

En base a los hallazgos neuquinos principalmente Adán y Alvarado (1999) sostienen que es necesario integrar los artefactos recuperados en ambos lados de la cordillera, ya que se trataría de un amplio espacio ocupado por poblaciones alfareras tempranas. Entre 1950 y 1960, Juan Schobinger y hacia finales de 1970 y mediados de 1980 Adan Hajduk describen una gran cantidad de piezas pintadas y modeladas características del variado repertorio alfarero del complejo Pitrén procedentes de la provincia de Neuquén, provenientes de colecciones privadas y museos (Schobinger 1958, 1969; Hajduk 1978, 1985). A partir de trabajos de excavación en las localidades de Aluminé-Moquehue y Bajo Añelo (Hajduk 1978, 1986) se describen los primeros contextos estratificados de alfarería Pitrén, junto a detalles importantes de otros aspectos de la cultura material de sus portadores en el ámbito oriental cordillerano.

En el sitio Bajo de Añelo (Hajduk 1978), Hadjuk describe una ocupación mono componentes tipo paradero-taller. Se destaca la presencia de alfarería con decoración con técnica negativa negro sobre rojo, pipas, tembetá, artefactos de molienda, artefactos líticos, junto a moluscos de procedencia marina, posiblemente del pacifico (Hajduk 1978). En el sitio Montículo Angostura, Departamento de Aluminé, cercano al paso de Icalma, y a muy escasa distancia de las nacientes del río Bío-Bío (Adán y Alvarado 1999), este mismo autor describe la presencia abundante material lítico, cerámico, pipas y restos orgánicos. La alfarería estaba compuesta por ollas y jarros, algunas decoradas con pintura resistente desde los niveles Moquehue I datados en $1.050 \mathrm{dC}$, junto a decoración por raspado, agregado de material o pastillaje, y círculos y líneas incisas. Otros rasgos típicos del complejo Pitrén son asas bajo el borde, asas puente, cuellos cortos subcilíndricos, doble cuellos, formas de más de un gollete y golletes con representaciones antropomorfas (Hajduk 1978, 1986; Adán y Alvarado 1999).

Años más tarde, entre los materiales cerámicos del sitio Chenque Haichol, Fernández describe la presencia de cerámica pintada negativa negra-rojo (Fernández 1988-89), típicas del repertorio habitualmente más conocido de la alfarería Pitrén junto a otras, pintadas rojo sobre blanco pertenecientes al alfarero tardío o Vergel-Valdivia.

En el sitio Alero los Cipreses, margen norte del lago Trafúl, en contextos datados en $840+/-9$ AP y 1.510+/-90 AP, se registró un componente asociado a actividades de caza y recolección, mantenimiento de artefactos líticos, y asociado a moluscos del pacífico, también aparecen fragmentos de alfarería principalmente monocroma, con decoración incisa y pintada en negativo negro sobre rojo, de adscripción Pitrén (Silveira 1996).

En inmediaciones del Parque Nacional Copahue, en ambientes de lagos y bosques de Pehuén (Araucaria arucana) Albornoz y Hajduk (1999) describen al menos 30 sitios arqueológicos. Entre estos, Hualcupén Superior II, Arroyo Dulce IV, y uno de los niveles de la cueva Puerta Tropote I, 
presentan tiestos decorados con pigmento negro aplicado sobre fondo rojo mediante técnica de pintura resistente. Se trata de sitios residenciales a cielo abierto y campamentos transitorios bajo reparo rocoso. Si bien en varios sitios se cuenta con materiales similares al alfarero tardío de Chile, como Vergel-Valdivia, la adscripción cronológica precolombina de los artefactos Pitrén con pintura resistente han sido confirmado mediante la datación por termoluminiscencia de un tiesto superficial recuperado en Arroyo Dulce IV arrojando una fecha de 980 +/- 100 dC (Albornoz y Hajduk 1999).

En el año 2006, uno de nosotros presentó los resultados parciales sobre la caracterización de la alfarería de un sitio a cielo abierto datado entre 750 y 1.100 AP, ubicado a orillas del lago Meliquina, en el cual, junto con artefactos líticos (puntas pedunculadas pequeñas y otros artefactos poco formatizados) manufacturados con obsidiana como materia prima mayoritaria se encontraron pipas, hachas, adornos. Se definió una economía vinculada a la caza y a la recolección de especies boscosas y lacustres como huemul y pudú, carnívoros, roedores, aves, moluscos y peces. Se identificó abundante alfarería, que incluía asas puente y emplazadas debajo del cuello, asas bifurcadas y pintura negativa negra sobre rojo, junto a decoraciones geométricas, incisas y en bandas al pastillaje (Pérez 2006).

Recientemente se ha descrito un fragmento de alfarería con posible decoración con pintura resistente en el sitio Paredón Lanfré, en ambiente de bosques de la Comarca Andina del Paralelo 42으. lat. Sur, provincia de Chubut (Bellelli et al. 2008).

Finalmente, un fragmento con posible pintura resistente habría sido descrito en el sitio Abrigo Pilcaniyeu, Provincia de Río Negro (Bellelli 1991).

En suma, la presencia de sitios y artefactos caracterizables como emparentados o similares al complejo Pitrén, corresponden a sitios habitacionales excavados sistemáticamente, a cielo abierto y bajo reparo rocoso (ver Hajduk et al. 1978, 1986; Fernández 1988-89; Albornoz y Hajduk 1999; Pérez 2006; Silveira 1996), aunque también hay registros recientes en Chubut (Bellelli et al. 2008). Al igual que los sitios de la precordillera occidental, corresponden a contextos asociados a caza y recolección $y$ con vinculaciones directas o indirectas en ciertos casos a la costa pacifica. Se presume que parte de los materiales de colecciones museográficas y parti- culares descritos por Schobinger y Hajduk provienen de contextos funerarios (Schobinger 1958, 1969; Hajduk 1978, 1985). El área de dispersión de esta alfarería en territorio neuquino, se corresponde con la colindante contrapartida occidental (chilena) propuesta para la territorialidad de este complejo alfarero. Existen otras menciones en áreas distantes, aunque esperan la confirmación de su caracterización (Bellelli 1991; Bellelli et al. 2008). En los contextos argentinos, la alfarería Pitrén se caracteriza por presentar las modalidades pintado con técnica resistente negro sobre rojo y modelado, además hay presencia de asas puentes, asas bifurcadas y asas emplazadas bajo el borde. No existe ninguna descripción hasta la fecha sobre la presencia de estilo improntas de hojas dentro del territorio argentino.

\section{Breve descripción de la técnica en negativo de las improntas de hojas}

Las vasijas con improntas de hojas en negativo de los contextos Pitrén chilenos, por lo general corresponden a cántaros monocromos. Es decir, son vasijas que carecen en su superficie de algún tipo de engobe o pigmento (Castro y Varela 1990) aplicado sobre el color original de la arcilla con que fueron manufacturadas.

En cuanto a la disposición de las hojas sobre la superficie de las piezas, un examen preliminar ha permitido visualizar ciertas variedades en cuanto a la frecuencia y emplazamiento de las mismas. Por un lado, hay vasijas en las cuales solo se observan hojas en la superficie exterior de la pieza, mientras que en otras éstas se registran por la cara externa e interna. Por otro lado, algunas vasijas presentan abundancia de improntas, que prácticamente se distribuyen por todo el cuerpo de la pieza, mientras que otras sólo las presentan en ciertos sectores, muchas veces en áreas del cuerpo cercanas al asa.

Siguiendo a Castro y Varela (1990) vemos que, técnicamente las improntas de hojas en las vasijas Pitrén fueron aplicadas a través de la técnica resistente. Esta habría consistido en la adhesión de hojas como material protector temporario (material resistente) sobre la superficie exterior y/o interior de las piezas previamente cocidas en atmósfera oxidante. Luego, la pieza habría sido introducida en una atmósfera saturada en monóxido de carbono con el fin de oscurecer la superficie (ahumado). Así 
finalmente, al desprenderse las hojas éstas dejarían su impronta en el área libre de monóxido, manteniéndose allí el color natural de la arcilla cocida. Esto último operaría para las vasijas monocromas, ya que en aquellas vasijas en las cuales se habría aplicado engobe previamente al ahumado, al sacar las hojas sus improntas permitirían conservar zonas con el respectivo engobe.

Estéticamente el uso de esta técnica nos remite al recurso plástico conocido como "figura-fondo" (Castro y Varela 1990; Adán y Alvarado 1999), el cual permite la configuración de los motivos decorativos que se desean trasmitir, a través del contraste de colores. Por lo tanto, técnicamente esta modalidad implica el conocimiento de complicados procesos productivos para provocar los efectos plásticos deseados (Adán y Alvarado 1999).

Como fuera señalado más arriba, las improntas de hojas se observan mayoritariamente asociadas a piezas monocromas, lo cual es significativamente diferente a lo que sucede con las vasijas con diseños geométricos de líneas, puntos o campos en negativo, los cuales generalmente se dispusieron sobre superficies que previamente habrían sido engobadas con rojo (Adán y Alvarado 1999). Además, estos motivos geométricos fueron aplicados exclusivamente en las categorías jarros, ya sea simétricos o asimétricos, lo cual también marca una importante diferencia con las vasijas que poseen improntas de hojas, ya que estas últimas, se registran dentro de una amplia gama de tipos morfológicos de vasijas.

Pese a estas diferencias, existe una innegable cercanía tecnológica entre el uso de la técnica resistente que dio origen a los diseños geométricos Pitrén, con aquel proceso de manufactura que necesariamente debió ser usado para conseguir la presencia de improntas de hojas. Este antecedente sumado al hecho de que para conseguir el efecto de improntas en negativo, las hojas debieron ser dispuestas y adheridas sobre la superficie como material resistente, hacen pensar que la presencia de ellas podría no ser efecto de un accidente casual producto del proceso de manufactura (cocción) (Castro y Varela 1990). Por el contrario, podrían ser el resultado de un esperado y concientemente manipulado rasgo decorativo. Sin duda, sólo posteriores estudios experimentales permitirán arribar a inferencias más concluyentes al respecto.

\section{MATERIALES Y MÉTODOS}

La muestra que presentamos a continuación está compuesta por 5 artefactos cerámicos con improntas evidentes de hojas, 2 de los cuales provienen del Conjunto 1 (entierro humano), con un $\mathrm{N}$ total de 20 artefactos correspondientes a un MNI de 3 vasijas, 2 de las cuales presentan improntas de hojas. Los 3 artefactos restantes corresponden al Conjunto 2 (sitio habitacional) con un $\mathrm{N}$ total superior a 1000 artefactos y un MNI que superaría las 20 vasijas, 3 de las cuales presentan improntas de hojas. Los atributos tecnológicos considerados a nivel macroscópico (ojo desnudo, bajos aumentos y lupa binocular) contemplaron las siguientes variables: morfología, tamaño (longitud, anchura, espesor), alteraciones superficiales, inclusiones (clase, densidad, tamaño, distribución), textura, color, atmósfera de cocción, tratamiento de la superficie, técnica de decoración. Dado que la muestra incluye artefactos enteros y fragmentos, el grado de análisis de las muestras será dispar. Para la clasificación de los materiales utilizamos los criterios sintetizados en Shepard (1976) y Orton et al. (1995).

\section{DESCRIPCIÓN DE LOS MATERIALES Y SU CONTEXTO}

\section{CONJUNTO 1}

\section{Cordón Chapelco}

Este hallazgo corresponde a una intervención no sistemática y procede de la ladera Oeste del Cerro Comandante Díaz, barrio Arrayanes, Lote 15,

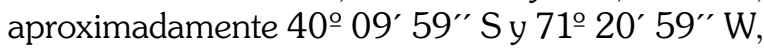
sector de amplia visión panorámica del Lago Lacar y valle donde actualmente se emplaza la ciudad de San Martín de los Andes (Fig. 2). Se encuentra asociado a un afloramiento rocoso dentro de un bosque de cipreses, área urbanizada y transitada en la actualidad. La muestra trata de una cantidad superior a los 20 artefactos cerámicos, los cuales corresponden a un número mínimo de tres vasijas. Dos son jarros completos, mientras que un tiesto con borde parece corresponder a un puco o cuenco. Uno de los jarros y el cuenco presentan atributos denominados "improntas de hojas", el restante jarro, bastante completo pese a su fragmentación, presenta 
pintura roja y emplazamiento del asa vertical en cuerpo y bajo el borde y otras características que remiten también a típicas variantes del Complejo Pitrén. Estos artefactos se encontraron asociados a los restos de un individuo juvenil de sexo indeterminado (menor a 6 años). Su dentición no ha terminado de eclosionar y la representación esqueletal parece ser bastante heterogénea, lo que sugiere la presencia del individuo completo y dada la ausencia de marcas o fracturas intencionales, posiblemente se trate de un entierro primario. Asociados a éstos, aparece además un número acotado de artefactos líticos (dos filos naturales con rastros de uso, uno en obsidiana y otro en sílice) y artefactos óseos con estado heterogéneo de meteorización, pero con algunos elementos postcraneales bien conservados y que presumimos -dado el contexto- eran parte del acompañamiento funerario. Los especimenes óseos presentan marcas de corte y cuentan entre ellos elementos diagnósticos a nivel taxonómico, como parte del maxilar con dentición y un fragmento proximal de radio-ulna, identificados como Hippocammelus bisulcus, cérvido de presencia cada vez mas habitual en el registro arqueológico del área (Pérez y Batres 2008). Se trata de un contexto intervenido por personal de la Subsecretaria de Cultura de San Martín de los Andes, quien detiene su saqueo por denuncia de pobladores locales, y culmina de extraer estos artefactos, depositándolos actualmente en el Museo Municipal Primeros Pobladores. Se cuenta con la ubicación exacta del hallazgo -el cual fue visitado por uno de nosotros con posterioridad- y su contexto. Pese a las disturbaciones registradas en el sitio, es posible caracterizarlo como un contexto alfarero con temporalidad previa al contacto europeo.

Descripción de los materiales:

\section{Artefacto 1:}

Procedencia: Cerro Comandante Díaz.

Contexto cronológico: sin dataciones, previo al siglo XVI.

Descripción: Vasija tipo jarra con fractura en borde con faltantes. Las medidas son $15 \mathrm{~cm}$ de altura, $14 \mathrm{~cm}$ de ancho y 0,5 cm de espesor en borde. Presenta boca restringida con labio evertido directo. Asa remachada emplazada verticalmente, de morfología acintada de sección subrectangular en cuello (debajo de borde) y cuerpo con dos apéndices o "protuberos" laterales adheridos en sector superior. Cuello tronco-cónico entrante. El cuerpo es globular con base aplanada (plano-convexa). La cocción es en atmósfera oxidante. La superficie externa se encuentra pulida y la interna alisada y pulida solo en sector interior de cuello. Presenta mica (predomina la muscovita blanca y en menor medida colorada de mayor tamaño) y cuarzo como antiplástico. Los porcentajes de antiplásticos o inclusiones son > $10 \%$ y los tamaños de los mismos varían entre < 0,5 a $3 \mathrm{~mm}$. Predominan las formas angulares y su distribución no es muy homogénea en cuanto a la mica que proviene naturalmente de la arcilla y más heterogénea en cuanto a los cuarzos, que son angulosos y de variado tamaño, lo que perece corresponder a un agregado a la pasta (Shepard 1976; Orton et al. 1995). La superficie es color beige con manchas de cocción color negras, y presenta impronta intencional y evidente de hojas distribuidas aleatoriamente en la superficie (Fig. 3a).

Artefacto 2:

Procedencia: Cerro Comandante Díaz.

Contexto cronológico: sin dataciones, previo al siglo XVI.

Descripción: Tiesto, fragmento de borde y cuerpo de $11 \mathrm{~cm}$ de alto, 9,5 cm de ancho y 0,5 a $0,6 \mathrm{~cm}$ de espesor. Correspondiente a un cuenco o puco de gran tamaño. El tiesto presenta reborde o engrosamiento de borde. Presenta superficie pulida en cara externa e interna. Como antiplástico se encuentran nuevamente la mica (pero ahora es biotita) y el cuarzo y otro no determinado en porcentajes $<10 \%$ y tamaños que varían entre 0,5 a $2 \mathrm{~mm}$. La mica es muy fina y parece ser una inclusión natural de la pasta, mientras que el cuarzo y el indeterminado son más grandes y angulosos, por lo tanto, podrían ser agregados intencionales de la pasta. Ésta aparece muy compacta y homogénea (Shepard 1976; Orton et al. 1995). La superficie es beige y presenta improntas evidentes de hojas en cara externa e interna (Fig. 3b).

\section{CONJUNTO 2}

\section{Lago Meliquina}

La "Localidad Arqueológica Meliquina" se encuentra ubicada a 18,5 km sureste de San Martín 
de los Andes, dentro del Departamento Lácar y Parque Nacional Lanín, provincia del Neuquén. Sus coordenadas aproximadas son 40 $19^{\prime}$ latitud Sur y $71^{\circ} 19^{\prime}$ longitud Oeste. Se encuentra a una altura de $970 \mathrm{msnm}$. Los materiales corresponden a dos sectores de un sitio unicomponente emplazado a cielo abierto a orillas del lago Meliquina, denominados Lago Meliquina, Faja Superior (LM, FS) y Faja Media (LM, FM), datado mediante ${ }^{14} \mathrm{C}$ en $730 \pm 80$ AP (LP 1559, carbón vegetal) y $920 \pm 60$ AP (LP 1721 , carbón vegetal), respectivamente. Las fajas altitudinales corresponden a antiguas terrazas del lago o capas frontales deltaicas, por lo que el depósito fue conformado por procesos hidrológicos (Pérez y Batres 2007). La presencia de artefactos arqueológicos se encuentra restringida a sedimentos limosos entre 0,15 a 0,40 m de profundidad, y arcillosos por debajo de los $0,40 \mathrm{~m}$. Si bien el sitio está expuesto a inundaciones -por eventos catastróficos-, se trataría de un ambiente de baja energía (Behrensmeyer 1975), el cual presenta sectores denudados en ambiente lacustre boscoso, cuya excavación expuso estructuras de combustión (rubefacción, vegetales carbonizados, rocas termóforas, huesos quemados), limitantes (postes de madera y rasgos negativos alineados y separados por distancia de 0,40 m), estructuras de contención de arcilla, y concentraciones de artefactos cerámicos y líticos que presentan secuencias de producción y remontajes que permiten inferir una buena conservación en general del contexto arqueológico (Pérez et al. 2008 en prensa). La fauna presente, vinculada a actividades de subsistencia (caza, pesca y recolección), es la típica de ambientes lacustres boscosos, entre los que se detallan cérvidos como huemul y pudú, carnívoros, (canidos y félidos), roedores, aves y abundantes recursos dulceacuícolas como peces y almejas (Pérez 2006; Pérez y Smith 2007; Pérez y Batres 2007, 2008). Se destaca la ausencia de especies típicas de ambientes esteparios y hasta transicionales como el guanaco y el ñandú y la presencia de moluscos marinos, algunos de distribución exclusiva de la costa pacífica (Pérez 2006).

Descripción de los materiales

Artefacto 3:

Procedencia: LM FM S1, BI Capa 5.

Contexto cronológico: anterior a $920 \pm 60$ AP (LP 1721)
Descripción: Tiesto de morfología indeterminable por fragmentación, sus medidas son $6,0 \mathrm{~cm}$ de alto, 4,2 de ancho y 0,6 cm de espesor. Superficie externa pulida y cara interna alisada, que permite inferir sectores de cuerpo en morfotipos de boca restringida como jarras y ollas. Los antiplásticos son mica (biotitica), cuarzo y feldespato, y se encuentran presentes en $<10 \%$ respecto de la pasta y en tamaños que varían entre 0,5 y 3,0 mm. La mica y el cuarzo son muy finos y parecen ser componentes naturales de la pasta, mientras que el feldespato y también algunos fragmentos de cuarzo de mayor tamaño y angulosos, distribuidos de manera menos homogénea, podrían ser agregados artificialmente a la pasta. La atmósfera de cocción es oxidante (Shepard 1976; Orton et al. 1995). La superficie es color beige y presenta impronta evidente de hoja en cara externa (Fig. 3c).

Artefacto 4: capa 3:

Procedencia: LM, FS S1, Cuadrícula DV,

Contexto cronológico: entre $730 \pm 80 \mathrm{AP}$ (LP 1559) y $750 \pm 50$ AP (LP 1569)

Descripción: Tiesto de morfología indeterminable por fragmentación de $3,1 \mathrm{~cm}$ de alto, $2,2 \mathrm{~cm}$ de ancho y $0,5 \mathrm{~cm}$ de espesor. Presenta superficie externa e interna pulida lo que sugiere que se trataría de parte de un cuello de jarra u olla restringida o del cuerpo de un cuenco de forma abierta. Los antiplásticos constituyen nuevamente $<10 \%$ y los tamaños de ellos van entre 0,5 y 2,0 mm. La mica (muscovita) está representada en forma muy escasa y es más abundante el cuarzo anguloso y subanguloso, presumiblemente agregado artificialmente a la pasta. Ésta es bastante homogénea, posiblemente está bien amasada o por características naturales. La atmósfera de cocción es oxidante (Shepard 1976; Orton et al. 1995). La superficie presenta un engobe beige claro, muy bien pulido en ambas caras y presenta una impronta evidente de hoja en su cara externa (Fig. 3d).

Artefacto 5: capa 3:

Procedencia: LM, FS, S1, cuadrícula AI, Contexto cronológico: $730 \pm 80$ AP (LP 1559) y $750 \pm 50$ AP (LP 1569)

Descripción: Tiesto de de morfología inde- 
terminable por fragmentación, de $3,0 \mathrm{~cm}$ de alto, 2,6 ancho y $0,35 \mathrm{~cm}$ de espesor. Tiesto de espesor muy delgado, se infiere un morfotipo de boca restringida a partir de presentar cara interna alisada y externa pulida, y globular, a partir de la curvatura que presenta respecto del tamaño del mismo. Los antiplásticos se encuentran en proporciones > 20\% respecto de la pasta, y sus tamaños son muy finos, entre 0,5 y $1,0 \mathrm{~mm}$. Se trata de mica, cuarzo y otra indeterminada. La mica (muscovita) parece ser un material incorporado de forma natural a la pasta (más finos y homogéneos) y otros parecen ser agregados (mayor tamaño, distribución más heterogénea y más angulosos). Tanto el cuarzo como los indeterminados son angulares y subangulares y aunque homogéneos, parecen ser agregados artificialmente a la pasta (Shepard 1976; Orton et al. 1995). La atmósfera de cocción es oxidante. Presenta impronta evidente de hoja en cara externa (Fig. 3e).

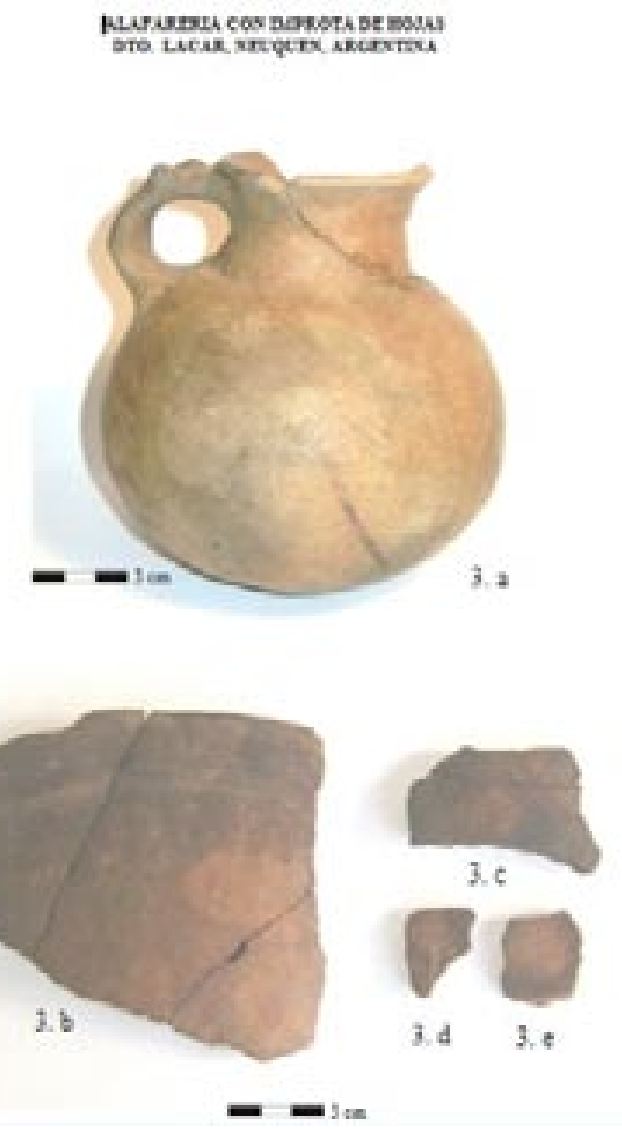

Fig. 3. Artefactos con improntas de hojas de Cerro Comandante Díaz y Lago Meliquina.

\section{ANÁLISIS COMPARATIVO DEL ATRIBUTO IMPRONTAS DE HOJAS EN NEGATIVO}

A modo de síntesis y siguiendo uno de los objetivos centrales de este escrito que se refiere a la contrastación de la presencia del complejo alfarero Pitrén en el ámbito cordillerano oriental, se describirá brevemente y en forma cualitativa las principales semejanzas observadas entre las vasijas de contextos chilenos que presentan improntas de hojas en negativo con aquellas descritas en el acápite anterior.

En este sentido podemos encontrar para ambas vertientes una serie de similitudes. Entre ellas destaca la presencia de este atributo en los mismos tipos morfológicos de vasijas: restringidas con cuello (jarros u ollas), las que poseen asas acintadas que se emplazan verticalmente desde el cuello (bajo el borde) hasta el cuerpo y en vasijas abiertas (pucos o cuencos), algunas de las cuales presentan bordes con reborde. En cuanto a la selectividad en el uso de las pastas para confeccionarlas, en ambos lados se registran pastas que incluyen como antiplástico abundante mica (biotita y moscovita). Por su parte, en términos decorativos la mayoría de estos cántaros poseen sus superficies monócromas (superficies externas pulidas), es decir, sin engobes como decoración.

Respecto al contexto de uso de estos cántaros, han podido observarse como parte del acompañamiento funerario en diversos cementerios chilenos, tanto de la cordillera lacustre como del valle (cementerio Los Chilcos, Pitrén, Escuela Collico, entre otros), y en el sitio funerario argentino Cerro Comandante Díaz en el ejido urbano de San Martin de los Andes, provincia de Neuquén. En ámbitos domésticos también han sido constatados, p.e en el sitio Puraquina, Licura-1, Flor del Lago-1 del lago Villarrica y en el sitio Antilef-1 del lago Calafquén, $y$ en territorio argentino en el sitio Lago Meliquina FS y FM, (Pérez 2006; Pérez et al. 2008) al Sureste de San Martín de los Andes. Los contextos de los sitios domésticos chilenos donde se aprecia cerámica con el rasgo improntas de hojas, presentan casi exclusivamente material cerámico, como sería el caso del sitio Puraquina, mientras que en otros como Licura, Flor del Lago-1 y Antilef-1, se observa además material lítico de tipo formatizado y desechos (Reyes et al. 2003-2004; Stern et al. 2009). 
A juzgar por los fechados obtenidos en el sitio de lago Meliquina, cronológicamente observamos que en ambas vertientes este rasgo aparece asociado a contextos cercanos al siglo $\mathrm{X}$ de nuestra era, aunque en Chile también se registra en acompañamientos funerarios de los primeros siglos de nuestra era.

\section{DISCUSIÓN}

Como fuera señalado anteriormente, uno de los objetivos principales que orientaba este trabajo se relacionaba con ofrecer un cuerpo de datos que permitiera abordar la problemática de la presencia de grupos cazadores-recolectores con territorialidad en ambientes lacustres boscosos de ambas vertientes de la cordillera de los Andes; estos grupos serían portadores de una desarrollada tecnología alfarera caracterizada como Complejo Pitrén. En este sentido, la descripción ofrecida sobre los conjuntos cerámicos obtenidos de San Martín de los Andes, con especial énfasis en el rasgo improntas de hojas, y de sus contextos de proveniencia, constituye un valioso aporte a la contrastación del modelo definido por Aldunate (1989), el cual establece la presencia de una contrapartida oriental y tardía del complejo Pitrén. Así, postulamos que si bien no está en discusión que buena parte de la cerámica Pitrén registrada en áreas orientales de los Andes pudo haber sido manufacturada en la vertiente occidental cordillerana, no podemos descartar la producción oriental de esta alfarería, la que deberíamos buscar entre las llamadas vasijas utilitarias, más abundantes y menos transportables en ciertos casos por su volumen. El carácter sedentario o la menor movilidad asociada al carácter agrícola de estos grupos alfareros es tema de debate, no hay pruebas concluyentes de que se trate de sociedades productoras de alimentos (Castro y Adán 2001), ya que muchas sociedades cazadoras recolectoras altamente móviles manufacturan y transportan alfarería (Barnet 1995; Hoppes 1995). En este sentido, la idea ha sido aportar un cuerpo de datos que permita ir discutiendo algunas de las apreciaciones que se han ido perpetuado, entre ellas la idea de un origen transcordillerano de la cerámica y de una posible territorialidad occidental de sus creadores y portadores, con lo cual la cordillera de los Andes aparece actuando más bien como una barrera entre distintos grupos étnicos en el pasado, más que como una frontera permeable.
A la fecha, varios artefactos cerámicos característicos del complejo alfarero Pitrén ya habían sido descritos en diversos contextos de la vertiente oriental cordillerana (Silveira 1987, 1996, 1999, 2003; Albornoz y Hajduk 1999; Hajduk 1978, 1985, 1986; Schobinger 1958, 1969; Fernández 1988-90; Pérez 2006; Bellelli 1991, Bellelli et al. 2007). Sin embargo, la mayoría de los autores no han ofrecido explicaciones interpretativas sobre la presencia de la misma, a excepción de los hallazgos estratificados de Aluminé-Moquehue y de Bajo Añelo, donde Hajduk reconoce una estrecha relación de parentesco entre artefactos cerámicos y contextos generales con los de los sitios de la vertiente occidental como Pitrén, Challupén 2 y Pucura 1 (Hajduk 1978). Los trabajos más recientes de síntesis que tratan cuestiones sobre alfarería a escala regional en la patagonia noroccidental no han abordado esta cuestión (Aldazabal y Eugenio 2004; Senatore 1996; Arrigoni 2002). Esto por tratarse de escaso material (pintado y modelado), el cual en algunos casos fue interpretado como el producto de "influencias araucanas". En otros sitios, como p.e Alero los Cipreses, estos materiales se atribuyeron en primera instancia a la explotación logística de esta zona por parte de grupos transcordilleranos (Silveira 1987), y más tarde, a partir de la integración de nuevos sitios, el mismo autor se inclinó por la hipótesis de una ocupación logística de sectores boscosos de la localidad Trafúl por parte de grupos esteparios (Silveira 1999). En el caso de los nuevos registros de la Comarca Andina del Paralelo $42^{\circ}$ lat. Sur, a pesar de ser evidente la circulación a través de pasos o corredores que incluyen ambas vertientes de la cordillera, en general sus contextos corresponden a ocupaciones de grupos esteparios que articulan logísticamente diversos pisos ecológicos de la vertiente oriental (Bellelli et al. 2008; Podesta et al. 2007; Matteuchi y Scheinsohn 2007). Debemos recordar sin embargo, que este sector cordillerano presenta una zona densamente forestada y de topográfia quebrada (Metteuchi y Scheinsohn 2007), casi inmediatamente articulada con la costa (Belleli et al. 2007; Podesta et al. 2007). Mientras que por encima del paralelo $41^{\circ}$ lat Sur, existe un espacio territorial amplio que comparte muchas características similares, y que en cuyo sector occidental se han caracterizado adaptaciones boscosas y lacustres desde al menos 11.500 años AP. Estas han sido 
registradas a partir de sitios como Monteverde y alero Marifilo-1, y de otros sitios cercanos a los lagos Calafquén y Villarrica con secuencias y contextos que muestran rasgos altamente tradicionales a lo largo del holoceno (Adán et al. 2001).

\section{SOBRE EL CARÁCTER PERMEABLE DE LA CORDILLERA DE LOS ANDES}

Respecto al carácter permeable de la cordillera, algunos investigadores la han caracterizado como una potencial barrera geográfica (Borrero 1994-95), aunque la evidencia arqueológica refleja que los ambientes boscosos de la patagonia noroccidental $y$ de su contrapartida occidental chilena fueron colonizados más tempranamente que la estepa (Borrero 2004). Entre Río Manso y cerca del paralelo $42^{\circ}$, la cordillera parece haber constituido un área permeable (Podesta et al. 2008; Bellelli 2008). Para Albornoz y Montero (2008), particularmente el área de Nahuel Huapi no habría constituido una barrera natural, actuando como una frontera permeable visible en diferentes contextos del poblamiento regional (Albornoz y Montero 2008). De manera coherente con estos postulados, en el año 2006 y a partir de nuevos sitios del Dto Lacar, Sur de Neuquén, se comenzó a trabajar la idea de que hacia los años 700-1.100 AP, pudo haber existido una territorialidad compartida entre los cazadores-recolectores adaptados a los ambientes lacustres boscosos de ambas vertientes de la cordillera Andina, ya que en sus contextos se observaban muchos aspectos similares con los que caracterizan a diversos asentamientos habitacionales de la región de Calafquen de Chile, asignados al Complejo Pitrén. De este modo, se puede señalar que a partir de los últimos años, han comenzado a surgir hipótesis contrarias al carácter limitante o fronterizo que hasta la fecha se ha postulado para la cordillera de los Andes en otras latitudes (Pérez 2006).

Así, para las localidades vecinas al área de estudio de este escrito, el carácter permeable de la Cordillera de los Andes puede ser sostenido a partir de diversos elementos, entre los que destacan la distribución del arte rupestre de la Modalidad del Ámbito Lacustre Boscoso del Noroeste de la Patagonia (Albornoz y Cuneo 2000), la variedad regional de la Tendencia Abstracta Geométrica Compleja (Gradín 1999) y de objetos decorados como toki, placas grabadas y alfarería con decoración incisa que a ambos lados de la cordillera, entre los $41^{\circ}$ y $43^{\circ}$ lat. Sur, comparte códigos visuales y simbólicos (Bellelli et al. 2008; Podesta et al. 2008).

Hacia el límite norte del área recién señalada, desde hace aproximadamente 10.000 años AP, a partir de evidencia mas variada como la presencia de moluscos marinos de presunta procedencia pacífica en sitios boscosos, transicionales y esteparios de Neuquén y Río Negro, también se ha señalado el carácter transitable que tuvo la cordillera andina (Hajduk et al. 2008; Crivelli y Montero 1993; Bellelli et al. 2007; Podesta et al. 2007; Albornoz y Montero 2008; Pérez y Batres 2007). Por su parte, en el área lacustre y boscosa del Nahuel Huapi, se describen en Isla Victoria restos humanos datados en 640 +-60 AP de características físicas similar a las poblaciones canoeras contemporáneas habitantes del archipiélago de Chiloé (Hajduk et al. 2008). La presencia de maíz y cebada en contextos inmediatamente posteriores, asociados a alfarería (Hajduk et al. 2008), es similar a la de otros contextos occidentales contemporáneos (Castro y Adán 2001; Aldunate 1989). Otra característica compartida es la posible tecnología de navegación atribuida a los pobladores de Isla Victoria hace casi 2.000 años AP y otros sitios emplazados en ambientes lacustres de acceso terrestre restringido en el lado oriental, y que en tiempos históricos sus rutas de circulación parecen ser de tipo hidrográficas por ambas vertientes de la cordillera hasta el pacífico (Casamiquela 1995; Hajduk et al. 2008, Albornoz et al. 2008, Braicovich y Caracothche 2008; Albornoz y Montero 2008). Por otro lado, algunas características morfológicas de la alfarería utilitaria en varios sitios del área Nahuel Huapi se inspiran en la vertiente occidental cordillerana, y posteriormente se registrará la presencia de alfarería más diagnóstica, como Valdivia o Vergel-Valdivia, de esta procedencia allende los Andes (Hajduk et al. 2008). Finalmente, al norte del Trafúl podemos mencionar que es más recurrente la presencia de alfarería modelada y pintada características de los conjuntos Pitrén (Hajduk 1978, 1985, 1986; Albornoz y Hajduk 1999; Silveira 1996, 1999; Pérez 2006, Pérez et al. 2007), asociada a contextos de caza y recolección. En este sector abunda además buena parte del variado repertorio de vasijas con decoración pintada roja sobre blanco de Vergel-Valdivia (Hajduk 
et al. 1978; Schobinger 1958; Fernández 1988-90), distribuida en ambientes lacustres boscosos hasta sectores noroccidentales del Neuquén, en algunos casos junto a otras variantes postcolombinas características por sus incrustaciones de loza hispana (Menghín 1962). En estos contextos plenamente alfareros, la presencia de moluscos marinos, muchos de ellos de distribución desde el océano pacífico, son más frecuentes y la diversidad de especies aumenta (Pérez y Batres 2007; Hajduk et al. 2008).

Respecto a las observaciones de que la cordillera no fue permeable para cierto tipo de materiales, como por ejemplo la obsidiana en el paralelo $42^{\circ}$ lat. sur, ésta puede ser una característica regional que no podríamos aún generalizar, ya que se han encontrado tanto fuentes en ambientes lacustres boscosos del Neuquén utilizadas a escalas espaciales muy reducidas, como otras de mayor distribución espacial encontradas muy cerca de la frontera chilena, y que proviene de fuentes desconocidas (Pérez y López 2009; López et al. 2009; López et al. 2009). No podemos descartar que algunos de los grupos químicos caracterizados como desconocidos en el sur del Neuquén, puedan proceder de la vertiente occidental andina.

\section{PROCESOS DE FORMACIÓN}

Como segundo tema a tratar en esta discusión, nos interesa enfatizar en algunos agentes que potencialmente afectaron a las vasijas y tiestos que presentan el rasgo improntas de hojas, ya que es un aspecto completamente desconocida regionalmente y que podría aportar a un mejor análisis.

El conjunto procedente del Cordón Chapelco se trata de un contexto funerario, por lo que los vestigios cerámicos presentan una buena conservación, al igual que ocurre con un importante número de contextos en la vertiente occidental cordillerana, aportando una gran cantidad de artefactos completos para su adecuada caracterización. Lago Meliquina se trata de un sitio habitacional a cielo abierto, por lo que la fragmentación de la muestra es mayor por su exposición a pisoteo, y por ende, la visibilidad de atributos como las improntas de hojas es más baja, por lo que se estima que los porcentajes de las mismas respecto del total están subrepresentadas. El grado de identificabilidad de estos atributos por ende es inversamente proporcional al grado de fragmen- tación de la muestra. En las muestras procedentes del Conjunto 1 (ceramio de contexto funerario) los atributos son muy evidentes, mientras que en el Conjunto 2 (fragmentería de contexto habitacional) se limita a atributos que corresponden sólo al 70\% de un tiesto, umbral que limita una asignación más precisa o válida a este atributo.

Si observamos otros contextos cerámicos de norpatagonia, varios de ellos refieren a la presencia de cerámica Pitrén por la presencia de tiestos con pintura resistente (Silveira 1987, 1999, 2003; Fernández 1988-90; Albornoz y Hajduk 1999; Hajduk 1978, 1986; Hajduk et al. 2004, Hajduk et al. 2008; Bellelli et al. 2007) y modelada (Hajduk 1985). Pese al grado de fragmentación de los artefactos cerámicos en estos conjuntos, la cerámica pintada resulta evidentemente más diagnóstica, ya que su identificabilidad está menos influenciada por el nivel de fragmentación. Por otro lado, los conjuntos muy fragmentados pudieron contener improntas de hojas, las cuales sin embargo, al formar parte de una muestra con muy baja expectativa de identificabilidad e inclusive al ser poco visibles como atributo tecnológico o estilístico, pudieron pasar desapercibidas una vez recuperadas. Esta situación también se verifica en el caso de Lago Meliquina, donde se ha podido identificar asociada a los tiestos con impronta de hojas, fragmentos muy pequeños de cerámica Pitrén con evidente pintura resistente sobre engobe rojo pulido, junto con asas puentes, asas con protúberos, pipas de arcilla y piedra, etc. (Pérez 2006).

Otro aspecto importante es la meteorización por exposición a la intemperie y efectos de crioturbación, que podrían afectar la identificabilidad de atributos de la superficie de la alfarería (Skibo et al. 1989). La muestra de lago Meliquina nos permite identificar que la meteorización y la crioturbación son realmente significativas, y mayormente podrían afectar a la superficie de los tiestos que presentan decoración pintada. Finalmente, el uso es otro factor que pudo obviamente alterar la visibilidad de ciertos atributos cerámicos, ya que la exposición directa al fuego para cocción de alimentos, podría causar desde una cobertura de los rasgos a partir de la homogeneización de la superficie por tiznado, hasta la pérdida de atributos por exfoliación o cambio de coloración, entre otros efectos. En suma, los procesos postdepositacionales inherentes al registro 
arqueológico de la alfarería en la región, deben ser profundizados para poder tener mayor control de aspectos que alteren notablemente la visibilidad de ciertos atributos, permitiendo caracterizar la presencia de estilos y técnicas alfareras, de modo de poder obtener un panorama más ajustado de su distribución espacial y temporal.

\section{CONSIDERACIONES FINALES}

La presencia del atributo cerámico "improntas de hojas en negativo" en vasijas tipo jarros y en formas abiertas registradas en dos conjuntos cerámicos trasandinos: uno de carácter mortuorio ubicado en Cerro Comandante Díaz y el otro de tipo habitacional localizado en Lago Meliquina, documentan y amplían cronológica y geográficamente la dispersión de uno de los rasgos cerámicos que caracterizan al Complejo Pitrén chileno. Uno de estos sitios presenta fechas cercanas al siglo X de nuestra era y el otro presumiblemente también sería tardío, y en ambos pueden ser constatados otros elementos asociados a la alfarería de esta tradición, como es el caso de asas verticales que nacen en el cuerpo y terminan bajo el borde, o bien, asas que presentan apéndices o protúberos y pintura resistente. Además, en estos yacimientos se observa el uso de tipos de arcillas preparadas con patrones tecnológicos similares a los observados en los conjuntos Pitrén chilenos. De esta manera, los contextos estudiados en San Martín de los Andes, nos remiten a grupos culturales que en tiempos tardíos están compartiendo a ambos lados de la Cordillera de los Andes, diversos aspectos ceramológicos de la tradición alfarera Pitrén, los cuales son activamente integrados en diversos ámbitos de su vida cotidiana.

La información que tenemos es aún fragmentaria y compleja. Por un lado, a causa de procesos de formación que llevan a una subrepresentación de este tipo de conjuntos, y por otro lado, debido a sesgos en el registro y análisis de los conjuntos cerámicos, donde las improntas de hojas, al igual que muchos otros atributos no modelados o pintados son mas dificultosos de identificar y caracterizar.

Dentro de este panorama, consideramos que este trabajo constituye un aporte para la generación de nuevos modelos que permitan comenzar a pensar en ambas vertientes de la cordillera andina norpatagónica como partes integradas de un mismo espacio ecológico, el cual posiblemente fue ocupado intensivamente y de forma similar durante buena parte del holoceno tardío. En suma, postulamos que la presencia de alfarería de la tradición Pitrén en sectores de bosques templados del Neuquén y las similitudes observadas en el carácter de las ocupaciones de ambas vertientes, permiten plantear la posibilidad de que hacia el $1.000 \mathrm{dC}$ grupos cazadores recolectores estén ocupando los ambientes lacustres boscosos de ambos lados de los Andes como un sólo territorio.

\section{AGRADECIMIENTOS}

Deseamos expresar nuestra gratitud a la Estación Zootécnica Parque A. Diana S.A. por su inestimable apoyo. A la Administración de Parques Nacionales, Municipalidad de San Martín de los Andes. A la Sra. Intendente Luz Sapag. A Alejandra Lema, Dra. Paola Ramundo y Daniel Batres por las imágenes. A los investigadores y colegas que nos han facilitado información inédita indispensable. A los evaluadores anónimos por su valioso aporte para mejorar este trabajo. Además, comprometen nuestra gratitud el Proyecto FONDECYT 1060216 "Habitando bosques lagos y volcanes: comparación de las ocupaciones Arcaico y Alfarero Temprano en los ámbitos cordilleranos Llaima-Lonquimay y Villarrica-Lanín (395)". Por último, este trabajo forma parte del proyecto UBA 840162, Arqueología del bosque meridional neuquino y su relación con sitios del área Paso Limay, estepa rionegrina y sectores transicionales.

\section{BIBLIOGRAFÍA}

ADÁN, L. 1997. Sistematización de la cerámica del Complejo Pitrén. Descripción de la metodología empleada. En: Actas del XIV Congreso Nacional de Arqueología Chilena. Contribución Arqueológica (5): 225-241. Copiapó.

ADÁN, L. y R. MERA. 1997a. Acerca de la distribución espacial y temporal del Complejo Pitrén. Una revaluación a partir del estudio sistemático de colecciones. Boletín de la Sociedad Chilena de Arqueología (24): 33-37.

ADÁN, L. y R. MERA. 1997b. La Tradición Pitrén. Una tipología alfarera, su distribución espacial y temporal. Informe Fondecyt 1950823. Valdivia. MS.

ADÁN, L. y M. ALVARADO. 1999. Análisis de colecciones alfareras pertenecientes al complejo Pitrén: Una aproxi- 
mación desde la arqueología y la estética. En: Soplando en el viento. Actas III Jornadas de Arqueología de la Patagonia. pp. 245-268. Editado por J.B Belardi, P. M Fernández, R. A Goñi, A.G Guráieb y M. De Nigris. Universidad Nacional del Comahue e INAPL NeuquénBuenos Aires.

ADÁN, L. y V. REYES. 2000. Sitio Los Chilcos: descripción y análisis de un nuevo cementerio Pitrén en la región del Calafquén. Boletín de la Sociedad Chilena de Arqueología (30):30-40.

ADÁN, L.; V. REYES y R. MERA. 2001. Ocupación humana de los bosques templados del centro-sur de Chile. Proposiciones acerca de un modo de vida tradicional. En: Actas del IV Congreso Chileno de Antropología, Tomo II: 1444-1455. Editado por M. Castro, A. Aravena y R. Sepúlveda. Colegio de Antropólogos de Chile y Universidad de Chile. Santiago.

ADÁN, L.; S. DONOSO y F. BAHAMONDES. 2007. Estudio de colecciones alfareras de la cuenca de Valdivia, décima región: conjunto alfarero Escuela Collico-1, Loncoche. Informe final proyecto FONDECYT 1040326. Valdivia. MS.

ALBORNOZ, A.M. y A. HAJDUK. 1999. Análisis del pasado aborigen y pautas de manejo del recurso arqueológico en el ámbito del Parque Provincial Copahue-Neuquén. En: Actas XII Congreso Nacional de Arqueología Argentina, T. III: pp.271-277. La Plata.

ALBORNOZ, A. M. y E. M. CÚNEO. 2000. Análisis comparativo de sitios con pictografías en ambientes lacustres boscosos de Patagonia septentrional: lagos Lácar y Nahuel Huapi (provincias del Neuquén y del [sic] Río Negro, República Argentina). En: Arte en las rocas. Arte rupestre, menhires y piedras de colores en Argentina, pp. 163-174. Editado por M. Podestá y M. de Hoyos. Sociedad Argentina de Antropología/INAPL. Buenos Aires.

ALBORNOZ, A. 2003. Estudios recientes del Arte Rupestre en la Provincia de Río Negro (desde fines de 1970 a la actualidad). Arqueología de Río Negro: 79-94. Editado por C. Gradín, A. Aguere y A. Albornoz. Publicación de la Secretaria de Estado de Acción Social de Río Negro. Carmen de Patagones. Buenos Aires.

ALBORNOZ, A.; A. HAJDUK; S. P. FORNELS; A. CANEIRO; y C. VÁZQUEZ. 2007. Sitio El Trébol: Identificación de pigmentos presentes en manifestaciones rupestres del ámbito boscoso lacustre del Nahuel Huapi, Rio Negro, Argentina. En: Patrimonio Cultural: la gestión, el arte, la arqueología y las ciencias exactas aplicadas, pp. 303-314. Editado por C.Vázquez y O.M. Palacios. Comisión Nacional de Energía Atómica.
ALBORNOZ, A. M. y G. MONTERO. 2008. Nahuel Huapi: Antropología e Historia Regional de un Área de Frontera. En: Soplando en el viento. Actas III Jornadas de Historia de la Patagonia, pp. 1-22. San Carlos de Bariloche.

ALDUNATE, C. 1989. Estadio Alfarero en el sur de Chile. En: Culturas de Chile. Prehistoria, pp. 329-348. Editado por J. Hidalgo, V Schiappaccase, H. Niemeyer, C. Aldunate e I. Solimano. Editorial Andrés Bello. Santiago.

ALDAZABAL, V. y E. EUGENIO. 2004. La cerámica del Sitio Rincón Chico 2. En: Contra viento y marea Arqueología de Patagonia, pp. 671-677. Editado por M. Civalero, P. Fernández y A. Guráieb. Instituto Nacional de Antropología y Pensamiento Latinoamericano y Sociedad Argentina de Antropología. Buenos Aires.

ARRIGONI, G. 2002. Los ceramistas prehistóricos del valle del Río Desaguadero, Parque Nacional Los Alerces, provincia del Chubut. Relaciones de la Sociedad Argentina de Antropología Tomo XXVII: 395-412.

BARNETT, W. 1995. Putting the Pot before the Horse Earliest Ceramics and the Neolithic Transition in the Western Mediterranean. En: The emergence of pottery. Technology and innovation in ancient societies. Editado por W. Barnett y J. Hoppes. Smithsonian Institution. Washington and London.

BEHRENSMEYER, A. K. 1975. The taphonomy and paleoecology of Plio-Pleistocene vertebrate assemblages east of Lake Rudolf, Kenia. Bulletin of Museum of Comparative Zoology (146):473-578.

BELLELLI, C. 1991. La cerámica del sitio La Figura 1. Comunicaciones Científicas del Museo de la Patagonia "Francisco Pascacio Moreno". Serie Antropología 2(2): 42-49. Bariloche.

BELLELLI, C., V. SCHEINSOHN, y M. PODESTÁ. 2008. Arqueología de Pasos Cordilleranos: un caso de estudio en Patagonia Norte Durante el Holoceno Tardío. En: en Boletín del Museo Chileno de Arte Precolombino, Vol.13, №2, pp. 37-55. Santiago.

BELARDI J. B. 2005. Paisajes arqueológicos: Un estudio comparativo de diferentes ambientes patagónicos. BAR International Series 1390. England.

BERDICHEWSKY, B. y M. CALVO. 1972-1973. Excavaciones en cementerios indígenas de la región de Calafquén. En Actas del VI Congreso de Arqueología Chilena. Boletín de Prehistoria, Número Especial:529-558. Santiago.

BORRERO, L. A. 1994/1995. Arqueología de la Patagonia. Palimsesto. Revista de Arqueología. № 4: 9-55. 
- 2004. The Archaeology of the Patagonian Deserts. Hunter-Gatherers in a Cold Desert. En: Desert Peoples. Archaeological Perspectives. Editado por P. Veth. P, Smith y P. Hiscock.

BRAICOVICH, R. y S. CARACOTCHE. 2008. Una biografía de las canoas monóxilas de la región andina norpatagónica. Perspectivas para su memoria y conservación. Historia de la Patagonia: Terceras Jornadas. Universidad Nacional del Comahue. Neuquén.

CABRERA, A. 1971. Fitogeografía de la República Argentina. Boletín de la Sociedad Argentina de Botánica (14):142. Buenos Aires.

CASAMIQUELA, R. 1995. Bosquejo de una Etnología de la provincia del Neuquén. Gobierno de la provincia del Neuquén, secretaría de estados de acciones sociales y comunitarias, subsecretaría de cultura. Ediciones La Guillotina. Neuquén.

CASTRO, V. y V. VARELA. 1990. Artífices del barro. Museo Chileno de Arte precolombino y Banco O'Higgins. Santiago.

CASTRO, V. y L. ADÁN. 2001. Abriendo diálogos. Una mirada entre la etnohistoria y la arqueología del área Centro-Sur de Chile: Asentamientos en la zona Mapuche. Revista Werken №2:5-35. Santiago.

COX, C. E. 1863. Viaje en las regiones septentrionales de la patagonia 1862-63. Santiago de Chile.

DONOSO, S. y M. GALLEGOS. 2008. Informe de análisis cerámico sitios Flor del Lago-1, Playa Negra-1, Licura-1 y Villarrica W8. Informe Fondecyt 1060216. Valdivia. MS.

GORDON, A. 1984. Huimpil. Un cementerio agroalfarero en el centro sur de Chile. Hombre, Cultura y Sociedad 2(2):33-37.

HAJDUK, A. 1978. Excepcionales ceramios de la provincia del Neuquén. Presencia de alfarería con decoración por pintura resistente en la provincia de Neuquén. Algunas consideraciones en torno a ella. Revista del Museo Provincial 1:103-121. Neuquén.

- 1985. Representaciones Antropomorfas en la Alfarería Arqueológica Neuquina. (Argentina). Comunicaciones Científicas del Museo de la Patagonia "Francisco P. Morero", Serie Antropología . Año 1, №1:1-20. San Carlos de Bariloche.

- 1986. Arqueología del Montículo Angostura. Primer fechado radiocarbónico Provincia del Neuquén. Museo Histórico Provincial, 1:1-43. Neuquén.

- 1991. Sitio arqueológico contacto hispano indígena Llao-Llao. Comunicaciones Científicas del Museo de la Patagonia "Francisco Pascasio Moreno", Serie Antropología 2(2): 1-24. Bariloche.
HAJDUK, A. y A. M. ALBORNOZ. 1999. El sitio Valle Encantado I. Su vinculación con otros sitios. Un esbozo de la problemática local diversa del Nahuel Huapi. En: Soplando en el viento. Actas de las III Jornadas de Arqueología de la Patagonia, pp. 371-391. Universidad Nacional del Comahue. Neuquén.

HAJDUK, A., ALBORNOZ, A. y M. LEZCANO. 2004. El "Mylodon" en el patio de atrás. Informe preliminar sobre los trabajos en el sitio El Trébol, ejido urbano de San Carlos de Bariloche, Provincia de Río Negro. En: Contra viento y marea. Arqueología de Patagonia, pp. 715-731. San Carlos de Bariloche.

HAJDUK, A., A. ALBORNOZ Y M. LEZCANO. 2007. Nuevos Pasos en pos de los Primeros Barilochenses. Arqueología del Parque Nacional Nahuel Huapi. En: Patrimonio Cultural: la gestión, el arte, la arqueología y las ciencias exactas aplicadas, pp.175-194. Editado por C.Vázquez y O.M. Palacios. Comisión Nacional de Energía Atómica.

HOOPES J. 1995. Interaction in Hunting and Gathering Societies as a Context for the Emergence of Pottery in the Central American Isthmus. En: The emergence of pottery. Technology and innovation in ancient societies. Editado por W. Barnett y J. Hoppes. Smithsonian Institute. Washington and London.

FERNÁNDEZ, J. 1988-1990. La cueva de Haichol. Arqueología de los pinares cordilleranos del Neuquén. Anales de Arqueología y Etnología 43-45:103-114. Neuquén.

LÓPEZ, L.; A. PÉREZ y C. R. STERN. 2009. Fuentes de aprovisionamiento y distribución de obsidianas en la provincia de Neuquén, (Noroeste de la Patagonia Argentina). Intersecciones en Antropología. En prensa.

LÓPEZ, L.; A. PÉREZ; D. BATRES, y C. R. STERN. 2009. Obsidian Artifact in La Pampa, Argentina, from Sources in Southwest Neuquén. IAOS Bulletin №41. En prensa.

MATTEUCHI, S. y V, SCHEINSHON. 2007. Materiales arqueológicos y patrones espaciales: tres años de trabajo en la intersección entre ecología del paisaje y la arqueología. Panorama de la Ecología del Paisaje en Argentina y Países Sudamericanos: 1-15. INTA.

MENGHIN, O. 1962. Estudios de prehistoria Araucana. Acta Praehistórica (3-4). Centro Argentino de Estudios Prehistóricos. Buenos Aires.

MENA, F. 1995. El ser humano y su larga relación con los bosques. Ambiente y Desarrollo 11 (1):63-69.

MERA, R. y L. ADÁN. 1997. Comunicación de nuevos sitios Pitrén a partir del estudio de colecciones. En: Actas del XIV Congreso Nacional de Arqueología Chilena. Contribución Arqueológica (5): 345-367. Copiapó. 
MERA, R., V. LUCERO, L. VÁSQUEZ, L. HARCHA y V. REYES. 2004. Sitios históricos tempranos de carácter defensivo: Sector oriental de la Villa Rica (1550-1602). Chungará vol.36 supl. espec. Tomo 1:175-186. Arica.

MERA, R. y D. MUNITA. 2006. Escuela Collico, un cementerio alfarero temprano en la cuenca de Valdivia. Aportes a la discusión del Complejo Pitrén. Boletín de la Sociedad Chilena de Arqueología (39):51-68.

MERMOZ, M.; E. RAMILO; C. CHEHEBAR; C. MARTÍN y S. CARACOTCHE. 1997. Parque Nacional Lanín: caracterización ecológica, recursos culturales y estado de conservación. En: Plan Preliminar de Manejo del Parque Nacional Lanín. Administración de Parques Nacionales. Bariloche.

MORENO, F. P. 1876. Viaje a la Patagonia Septentrional. Anales de la Sociedad Científica № 1. Buenos Aires.

OCAMPO, C.; R. MERA y P. RIVAS. 2001. Cementerios Pitrén en el By Pass de Temuco. En: Actas del IV Congreso Chileno de Antropología, Tomo II: 1444-1455. Editado por M. Castro, A. Aravena y R. Sepúlveda. Colegio de Antropólogos de Chile y Universidad de Chile. Santiago.

OLIVARES, M. 1874. Historia de la Companía de Jesús en Chile (1593-1736). Santiago, Chile.

ORTON, C.; P. TYERS y A. VINCE. 1995. Pottery in Archaeology. University Press. Cambridge.

PÉREZ, A. 2006. La Localidad Arqueológica "Lago Meliquina", Dpto. Lácar, Neuquén. El registro arqueológico del interior y borde de bosque en Norpatagonia. En: Actas del XVI Congreso Nacional de Arqueología Chilena. Valdivia. En prensa.

PÉREZ, A. y M. SMITH. 2007. Eficiencia depredadora y sistema de asentamiento e el bosque norpatagónico. La Localidad Arqueológica Meliquina, Parque Nacional Lanín, Neuquén. Las Ciencias. Revista científica de la Universidad Maimónides (1):67-78. Buenos Aires.

PÉREZ, A. y D. BATRES. 2007. Moluscos del sitio Lago Meliquina (Parque Nacional Lanín, Provincia de Neuquén, Argentina). En Actas de las Primeras Jornadas Nacionales de Cazadores-Recolectores. Santiago, Chile. En prensa.

- 2008. Los otros cazadores. La explotación de cérvidos en la Localidad Arqueológica Meliquina, Parque Nacional Lanín, República Argentina. Zooarqueología Hoy. Encuentros Hispano-Argentinos:89-108. Editado por Carlos Díez. Burgos. España.

PÉREZ, A.; M. SMITH y E. GRILLO. 2008. Implicancias tafonómicas de la composición faunística en la Localidad Arqueológica Meliquina, Parque Nacional Lanín, Pcia. de Neuquén, Argentina. Revista RUNA 29. Buenos Aires. En prensa.

PÉREZ, A. y L. LÓPEZ. 2009. Análisis por LA-ICP-MS para determinar las fuentes de aprovisionamiento de las obsidianas utilizadas en la Localidad Arqueológica Meliquina (Parque Nacional Lanín, Provincia de Neuquén). En: Actas de las Primeras Jornadas Nacionales de Arqueología de Cazadores-Recolectores. Santiago.

PARUELO, J.; A. BELTRÁN; E. JOBBÁGY; O. SALA y R. GOLLUSCIO. 1998. The climate of Patagonia: general patterns and controls on biotic processes. Ecología Austral (8): 85-101. Bariloche.

PODESTA, M.; C. BELLELLI; R. LABARCA; A.M. ALBORNOZ; A.B. BASINI y E. TROPEA. 2008. Arte rupestre en pasos cordilleranos del Bosque Andino Patagónico (El Manso, Región de Los Lagos y Provincia de Río Negro, Chile-Argentina). Magallania, Vol. 36(2): 143-153.

QUIROZ, D.; M. VÁSQUEZ y M. SÁNCHEZ. 1997. Quino-1, un sitio alfarero temprano en la región centro-sur: noticia y comentario para un fechado. Boletín de la Sociedad Chilena de Arqueología (24):11-14.

QUIROZ, D. y M. SÁNCHEZ. 2005. La secuencia Pitrén-El Vergel en Isla Mocha: soluciones de continuidad y distinciones culturales. En: Actas del XVI Congreso Nacional de Arqueología Chilena, pp. 369-378. Editado por el Museo de Historia Natural de Concepción, DIBAM y Sociedad Chilena de Arqueología. Escaparate Ediciones. Concepción.

REYES, V.; L. SANHUEZA y L. ADÁN. 2003-2004. Alfarería doméstica y funeraria de la Región del Calafquén. Revista Chilena de Antropología (17):151-179.

SÁNCHEZ, M.; D. QUIROZ y C. BECKER. 1994. Un sitio alfarero tardío en la Isla Mocha: P31-1. Boletín del Museo Regional de la Araucanía (5):103-110.

SÁNCHEZ, M. 1997. El período alfarero en la isla Mocha. En: La Isla de las palabras rotas, pp. 103-131. Compiladores D. Quiroz y M. Sánchez. Ediciones de la Biblioteca Nacional de Chile. Santiago.

SCHOBINGER J. 1958. Hallazgos Arqueológicos de la provincia de Neuquén. Lista descriptiva del material mobiliar. Anales de Arqueología y Etnología, Suplemento al Tomo XIII. (Mimeografiado), Mendoza.

SCHOBINGER J. 1969. Un notable cántaro ceremonial antropomorfo de la zona cordillerana del Neuquén (Argentina). En: Actas VII Congreso Nacional de Arqueología de Chile: 377-387.

SCHOBINGER, J. 1969. Prehistoria de Suramérica. Labor. Barcelona. 
SENATORE, X. 1996. Tecnología cerámica en el Área de Piedra del Águila, provincias de Río Negro y Neuquén. Prehistoria (2): 127-147. Buenos Aires.

SILVEIRA, M.1987. Investigación en el área boscosa del lago Trafúl, provincia de Neuquen. En: Actas de las I Jornadas de Arqueología de la Patagonia, pp. 295-303. Editado por Dirección Provincial de Cultura. Rawson.

- 1996. Alero Los Cipreses (Provincia del Neuquén, República Argentina). En: Arqueología Sólo Patagonia. Actas de las II Jornadas de Arqueología de la Patagonia, pp. 107-118. Editado por Julieta Gómez Otero. Centro Nacional Patagónico. Puerto Madryn.

- 1999. El Alero Lariviere: Un sitio en el bosque septentrional andino (departamento de Los Lagos, provincia de Neuquén, Argentina). En: Soplando en el Viento. Actas de las III Jornadas de Arqueología de la Patagonia, pp. 83-95. Editado por J.B Belardi, P. M Fernández, R. A Goñi, A.G Guráieb y M. De Nigris. Universidad Nacional del Comahue e INAPL. Neuquén-Buenos Aires.

- 2003. Las poblaciones prehistóricas e históricas en el área boscosa-ecotonal del lago Trafúl (provincia del Neuquén). En: Actas de las IV Congreso Argentino de Americanistas. Tomo I, pp. 399-418. Sociedad Argentina de Americanistas. Buenos Aires.

SCHIFFER, M. 1987. Formation processes of the archaeological record. University of New Mexico Press. Alburquerque.

SKIBO, J.; M. SCHIFFER y K. REID.1989. Organic-tempered Pottery: an experimental study. American Antiquity 54(1): 122-146.

SHEPARD, A. 1976. Ceramics for the Archaeologist. Carnegie Institution of Washington D.C.

STERN, C.; C. GARCÍA; X. NAVARRO y J. MUÑOZ. 2009. Fuentes y Distribución de Diferentes Tipos de Obsidianas en Sitios Arqueológicos de Chile Centro-Sur (38-44 Lat. Sur). Magallania. En prensa.

VELÁSQUEZ, H. y L. ADÁN. 2004. Marifilo 1:Evidencias arqueofaunísticas para entender las relaciones hombre y bosques templados en los sistemas lacustres cordilleranos del centro sur de Chile. En: Contra viento y marea. Arqueología de la Patagonia, pp. 507-519. Editado por T. Civalero, P. Fernández y G. Guráieb. Instituto Nacional de Antropología y Pensamiento Latinoamericano y Sociedad Argentina de Antropología. Buenos Aires. 